\title{
Effect of delayed versus early umbilical cord clamping on neonatal outcomes and iron status at 4 months: a randomised controlled trial
}

\author{
(ब) $(1) \Theta$ OPEN ACCESS
}

\author{
Ola Andersson consultant in neonatology ${ }^{12}$, Lena Hellström-Westas professor of perinatal medicine ${ }^{2}$, \\ Dan Andersson head of departments of paediatrics, obstetrics and gynaecology ${ }^{1}$, Magnus Domellöf \\ associate professor, head of paediatrics ${ }^{3}$
}

'Department of Paediatrics, Hospital of Halland, Halmstad, SE-301 85 Halmstad, Sweden; ${ }^{2}$ Department of Women's and Children's Health, Uppsala University, SE-751 85 Uppsala, Sweden; ${ }^{3}$ Department of Clinical Sciences, Paediatrics, Umeå University, SE-901 85 Umeå, Sweden

\begin{abstract}
Objective To investigate the effects of delayed umbilical cord clamping, compared with early clamping, on infant iron status at 4 months of age in a European setting.

Design Randomised controlled trial.

Setting Swedish county hospital.

Participants 400 full term infants born after a low risk pregnancy.

Intervention Infants were randomised to delayed umbilical cord clamping ( $\geq 180$ seconds after delivery) or early clamping ( $\leq 10$ seconds after delivery).
\end{abstract}

Main outcome measures Haemoglobin and iron status at 4 months of age with the power estimate based on serum ferritin levels. Secondary outcomes included neonatal anaemia, early respiratory symptoms, polycythaemia, and need for phototherapy.

Results At 4 months of age, infants showed no significant differences in haemoglobin concentration between the groups, but infants subjected to delayed cord clamping had $45 \%$ (95\% confidence interval $23 \%$ to $71 \%)$ higher mean ferritin concentration $(117 \mu \mathrm{g} / \mathrm{L} v 81 \mu \mathrm{g} / \mathrm{L}, \mathrm{P}<0.001)$ and a lower prevalence of iron deficiency $(1$ (0.6\%) $v 10$ (5.7\%), $\mathrm{P}=0.01$, relative risk reduction 0.90 ; number needed to treat=20 (17 to 67)). As for secondary outcomes, the delayed cord clamping group had lower prevalence of neonatal anaemia at 2 days of age $(2(1.2 \%) v 10(6.3 \%)$, $\mathrm{P}=0.02$, relative risk reduction 0.80 , number needed to treat 20 (15 to 111)). There were no significant differences between groups in postnatal respiratory symptoms, polycythaemia, or hyperbilirubinaemia requiring phototherapy.

Conclusions Delayed cord clamping, compared with early clamping, resulted in improved iron status and reduced prevalence of iron deficiency at 4 months of age, and reduced prevalence of neonatal anaemia, without demonstrable adverse effects. As iron deficiency in infants even without anaemia has been associated with impaired development, delayed cord clamping seems to benefit full term infants even in regions with a relatively low prevalence of iron deficiency anaemia.

Trial registration Clinical Trials NCT01245296.

\section{Introduction}

Iron deficiency and iron deficiency anaemia are major public health problems in young children worldwide, and are associated with poor neurodevelopment. Delayed umbilical cord clamping has been suggested as a measure to prevent infant iron deficiency, ${ }^{1}$ but we lack data concerning its health benefits and possible adverse effects, especially in high income countries.

Young children are at particular risk of iron deficiency because of high iron requirements during rapid growth in combination with low iron intake. Globally, about a quarter of preschool children have iron deficiency anaemia, the most severe form of iron deficiency. In Europe, the prevalence of iron deficiency anaemia is $3-7 \%$ among young children, and the prevalence of iron deficiency has been reported to be as high as $26 \% .^{2-4}$ Iron is essential for several aspects of brain development, including myelination, dendritogenesis, neurotransmitter function, and neuronal and glial energy metabolism. ${ }^{5}$ Iron deficiency anaemia in young children is associated with long lasting cognitive and behavioural deficits. ${ }^{78}$ Iron deficiency without established anaemia has also been associated with altered affective responding, impaired motor development, and cognitive delays. ${ }^{9-12}$ Two recent meta-analyses have concluded that iron supplementation improves psychomotor and mental development in infants and children. ${ }^{1314}$ Thus, the available evidence suggests that it is important to prevent iron deficiency in infants in order to achieve optimal brain development.

During the first minutes after birth, the newborn infant may receive a substantial blood transfusion from the placenta. A 
term newborn held $10 \mathrm{~cm}$ below the level of the uterus during the first three minutes of life increases its blood volume by an average of $32 \% .{ }^{15}$ Delayed cord clamping, usually defined as ligation of the umbilical cord 2-3 minutes after birth or when cord pulsations stop, will thus result in a larger placental transfusion than early cord clamping performed immediately after delivery. ${ }^{16}$

Only a few controlled trials have assessed effects of delayed cord clamping on infant health beyond the neonatal period.

These studies were all performed in low and middle income populations with a high prevalence of iron deficiency anaemia (India, ${ }^{17}{ }^{18}$ Guatemala,${ }^{19}$ Mexico,${ }^{20}$ and Zambia ${ }^{21}$ ). Two meta-analyses including these studies concluded that delayed cord clamping results in higher levels of serum ferritin at 3-6 months of age. ${ }^{162}$ The timing of umbilical cord clamping could be important also in high income countries in view of the relatively high reported prevalence of iron deficiency in Europe and the US. ${ }^{23}{ }^{24}$ However, there are no available data concerning health effects of delayed cord clamping beyond the neonatal period in term newborn infants in high income countries.

Some studies suggest that delayed cord clamping may have adverse neonatal effects with increased risk of respiratory symptoms,${ }^{25}$ polycythaemia, ${ }^{26}$ hyperbilirubinaemia, ${ }^{27}$ and need of phototherapy. ${ }^{162}$ In many high income countries there is current debate whether early or delayed cord clamping is preferable. A recent survey of policies at European delivery units showed large differences in cord clamping practices, both between and within countries, with early cord clamping being the dominating practice. ${ }^{28}$ We therefore undertook this randomised clinical trial to compare the effects of delayed and early cord clamping on iron status, including haemoglobin, at 4 months of age in healthy, term Swedish infants.

\section{Methods}

\section{Trial design}

We conducted a randomised controlled trial (parallel group study with 1:1 randomisation) comparing delayed and early cord clamping. The study was conducted between April 2008 and September 2009 at the Hospital of Halland, Halmstad, Sweden.

\section{Participants}

Pregnant women were eligible if they met the following criteria: non-smoking; healthy (no haemolytic disease, no treatment with any of the following drugs (anticonvulsants, antidepressants, thyroid hormone, insulin, chemotherapy, or cortisone)); normal pregnancy (no pre-eclampsia, no diabetes, no prolonged rupture of membranes or signs of infection); singleton; term pregnancy (gestational age $37^{+0}$ to $41^{+6}$ weeks); expected vaginal delivery with cephalic presentation. The mother also had to understand Swedish well enough to participate in the study and live close enough to the hospital to be willing to return for follow-up after four months. Exclusion criteria were serious congenital malformations, syndromes, or other congenital diseases that could affect the outcome measures.

Pregnant women were first given information about the trial at the antenatal healthcare centre. Those fulfilling the inclusion criteria at the time of admission to the delivery ward were again informed about the study by the attending midwife. Written informed consent was obtained, from both parents when possible. The study was approved by the regional ethical review board at Lund University (41/2008).

\section{Intervention}

When delivery was imminent (expected within 10 minutes), the midwife opened a sealed, numbered, opaque envelope containing the treatment allocation. The interventions consisted of delayed clamping of the umbilical cord ( $\geq 180$ seconds after delivery) or early clamping of the umbilical cord $(\leq 10 \mathrm{~s})$. In both intervention arms, the midwife was instructed to hold the newborn infant at a level about $20 \mathrm{~cm}$ below the vulva for 30 seconds and then place the baby on the mother's abdomen (20 $\mathrm{cm}$ was chosen as a practically obtainable level because of the facility to fold down the lower part of the delivery bed). Babies born by caesarean section were placed in the mother's lap before clamping in accordance with clinical routines. Oxytocin (10 IU) was administered intravenously immediately after cord clamping. The time from complete delivery of the baby to the first clamp on the umbilical cord was measured with a stopwatch by the midwife's assistant.

Venous and arterial cord blood samples for assessment of acid-base status were taken within 30 seconds from the unclamped cord in the delayed cord clamping group and within 10 minutes from the double clamped segment of the umbilical cord in the early clamping group. Study samples were taken from the clamped umbilical cord in both groups. The remaining fetal blood in the placenta was measured by placing the free end of the cut umbilical cord in a measuring glass and elevating the placenta until all blood had been drained. All other aspects of obstetric care were managed according to standard practice at the hospital. All staff in the delivery unit were trained in the study procedures before the trial started. Early cord clamping was the clinical standard procedure in the hospital before the study.

\section{Follow-up}

After the delivery, the babies were cared for according to clinical routines, and early breast feeding was encouraged. As part of the study, the infant was assessed at 1 and 6 hours by the midwife, who recorded if the baby had been breast fed and the presence of respiratory symptoms (that is, respiratory rate $>60$ breaths/minute, presence of nostril flaring, grunting, or intercostal retractions).

Infants stayed at the postnatal ward with their mothers for two or three days, except for well babies whose mothers preferred to leave the hospital earlier and infants who were admitted to the neonatal unit. All infants were examined by a physician during the first 72 hours, in accordance with clinical routines. All neonatal diagnoses were reported in the study protocol. At 48-72 hours after birth, study samples were taken by a midwife or a neonatal nurse in conjunction with routine venous blood sampling for metabolic screening. Results from any additional blood samples that were taken on clinical indications were also recorded in the study protocol. The results from study samples were reviewed once a week by a physician, and appropriate action was taken if necessary. Six infants were considered to have anaemia at 2 days of age and were referred for further diagnostics, but none needed treatment.

At 4 months of age, infants were scheduled for a follow-up visit including blood sampling and weight and length measurements. Venous blood sampling was performed after application of a local anaesthetic (EMLA, AstraZeneca). Before the visit, parents were asked to complete a three day food diary to assess whether the infant was exclusively or partially breast fed and whether formula or solids were given. 


\section{Additional data collection}

The following information was collected from maternal healthcare records: reported illness, medication, parity, weight, height, body mass index, smoking habits, blood group Rhesus factor status, and haemoglobin concentration at the time of admission to antenatal care. The median duration of pregnancy at this visit was 76 days (interquartile range 68 to 84). If the objective of the randomised intervention (that is, $\geq 180$ s between delivery and umbilical cord clamping for delayed clamping or $\leq 10$ s for early clamping) was not achieved, the reason for this was noted.

\section{Blood samples}

Umbilical cord blood was analysed for complete blood count (haemoglobin, packed cell volume, mean cell volume, mean cell haemoglobin concentration, reticulocyte count, and reticulocyte haemoglobin); iron status (serum iron, transferrin, serum ferritin, transferrin saturation, and soluble transferrin receptors); and $\mathrm{C}$ reactive protein. At 2 days of age, venous blood was analysed for complete blood count, iron status, C reactive protein, and bilirubin. At 4 months, venous blood samples were analysed for complete blood count, iron status, and $\mathrm{C}$ reactive protein.

Blood was collected in EDTA tubes (BD Vacutainer, Plymouth, UK) for complete blood count, and in serum separator tubes (BD Vacutainer) for iron status, bilirubin, and $\mathrm{C}$ reactive protein.

Blood samples were stored for a maximum of one hour in room temperature and then transported for analysis to the hospital clinical chemistry laboratory, where analyses were performed within one hour. Complete blood counts were analysed with an automated haematology analyser (Sysmex XE 2100, Sysmex, Kobe, Japan). Iron status indicators, bilirubin, and $\mathrm{C}$ reactive protein were analysed with Cobas 6000 (Roche Diagnostics, Basel, Switzerland).

We used the following definitions:

At 2 days

Anaemia-haemoglobin $<145 \mathrm{~g} / \mathrm{L}^{29}$

Polycythaemia—packed cell volume $>0.65^{30}$

Hyperbilirubinaemia—bilirubin $>257 \mu \mathrm{mol} / \mathrm{L}$ (corresponding to $15 \mathrm{mg} / \mathrm{dL}$ )

At 4 months

Anaemia-haemoglobin $<105 \mathrm{~g} / \mathrm{L}^{31}$

Iron deficiency $-\geq 2$ indicators of iron status outside reference range (ferritin $<20 \mu \mathrm{g} / \mathrm{L},{ }^{31}$ mean cell volume $<73$ $\mathrm{fL},{ }^{31}$ transferrin saturation $<10 \%,{ }^{32}$ soluble transferrin receptor $>7 \mathrm{mg} / \mathrm{L}$ ). (The soluble transferrin receptor cut-off value for the Roche immunoturbidimetric assay was calculated from the established cut-off value of $11 \mathrm{mg} / \mathrm{L}^{31}$ for the Ramco enzyme linked immunosorbent assay (ELISA) using the regression equation described by Pfeiffer et $\mathrm{al}^{33}$ )

The log ratio of soluble transferrin receptor to ferritin (logTfR/Fer-ratio) was calculated. ${ }^{34}$ Soluble transferrin receptor was converted to values corresponding to the Ramco ELISA ${ }^{33}$ and then transformed to $\mu \mathrm{g} / \mathrm{L}$. The result was divided with the ferritin, and the logarithm (base 10) of the ratio was used. Total body iron $(\mathrm{mg} / \mathrm{kg})$ was approximated by the equation $-\left(\log\right.$ TfR/Fer-ratio-2.8229)/0.1207. ${ }^{35}$

\section{Primary outcome}

The primary outcome was infant haemoglobin and iron status (measured as serum ferritin, transferrin saturation, soluble transferrin receptors, reticulocyte haemoglobin, mean cell volume, mean cell haemoglobin concentration) at 4 months of age. To further assess iron status, we calculated iron deficiency, $\log \mathrm{TfR} /$ Fer-ratio, and total body iron as described.

\section{Secondary outcomes}

In this paper we report neonatal morbidity (including anaemia, polycythaemia, need for phototherapy, and respiratory symptoms). Other secondary outcomes are beyond the scope of the current paper, and will be reported separately: maternal postpartum haemorrhage and rates of successful umbilical arterial blood samples in relation to allocation group; neonatal serum immunoglobulin $\mathrm{G}$ level and infections during the first four months of life; effects of delayed and early cord clamping on iron status and haemoglobin at 12 months of age;

psychomotor development at 4 and 12 months of age assessed by the Ages and Stages Questionnaire; reticulocyte haemoglobin as a marker of neonatal and infant iron stores.

\section{Sample size}

As ferritin is the most sensitive indicator of iron status and has been shown to be the most efficient indicator of iron interventions, ${ }^{36}$ it was chosen for estimating the necessary group size. Evidence regarding the effects of early versus late cord clamping comes from a few trials in low or middle income countries, and we designed our study to be comparable with them. Beyond the neonatal period, the main effect observed in those studies is that delayed cord clamping leads to an increase in ferritin concentration at 3-6 months of age, which has been considered of importance to public health. ${ }^{1620} 22 \mathrm{We}$ therefore chose iron status at 4 months as our main outcome and powered the study to find a difference in ferritin concentration.

A prestudy power analysis showed that a group size of 150 would allow us to find a difference of $29 \%$ in geometric mean serum ferritin concentration between groups at 4 months of age with a power of $80 \%$ and a significance level of 0.05 , assuming a mean serum ferritin concentration of $110 \mu \mathrm{g} / \mathrm{L}$ in the delayed cord clamping group. ${ }^{37}$ The study was thus powered to find a slightly smaller difference in ferritin concentration than in a previous study in Mexico ${ }^{20}$ where the delayed cord clamping group had 34\% higher serum ferritin concentration at 6 months. Allowing for an attrition of $25 \%$, we included 200 participants in each group.

\section{Randomisation}

Randomisation was performed by one of the investigators (MD) in advance by computer in blocks of 20 using the random number generator in MS Excel (Microsoft, Seattle, WA, USA).

\section{Blinding}

The study design precluded either the mother giving birth or the midwife performing the intervention being blinded. Physicians performing neonatal examinations, staff members responsible for collection of blood samples and background data, and laboratory staff performing analyses of blood samples were blinded to each infant's allocation group.

\section{Statistical analysis}

For group comparisons of continuous variables, we used Student's $t$ test for variables with normal distribution. For variables with skewed distribution, we used Mann-Whitney U test for group comparisons and used Hodges and Lehmann estimator $^{38}$ for confidence intervals across groups. Ferritin 
concentration was $\log _{10}$ transformed for analysis. Categorical variables were compared between groups by using Fisher's exact test. We used SPSS for Windows, version 18.0 (SPSS, Chicago, IL, USA). We calculated the numbers needed to treat, relative risk reduction, and their confidence intervals using the web based JavaStat calculator. ${ }^{39}$ A P value $<0.05$ was considered significant.

All analyses were made on an intention to treat basis, except for 12 cases (four allocated delayed cord clamping, eight allocated early clamping) that were erroneously included in the study despite not fulfilling inclusion criteria. Of the 382 children finally analysed, 334 received the allocated intervention (168 for delayed clamping, 166 for early clamping) (figure $\downarrow$ ).

We redid all analyses for the main and secondary outcomes, including cases of protocol breach at inclusion as well as per protocol $(n=334)$, and this did not alter the results. We also did a sensitivity analysis for outcomes at 4 months of age by calculating imputed results for dropouts after 2 days of age $(n=25)$, and the results did not change.

\section{Results}

Four hundred mother-infant dyads participated in the study. Participants were recruited for 13 months from April 2008 to May 2009; with a four month follow-up from August 2008 to September 2009. In total, 382 infants constituted the study population, and their data were analysed according to intention to treat. Of these infants, $334(87 \%)$ received the allocated intervention, and 350 (92\%) were evaluated for the main outcome at 4 months of age (figure $\downarrow$ ).

\section{Baseline data}

There were no significant differences between the delayed cord clamping and early clamping groups with respect to maternal characteristics or neonatal baseline data (table $1 \Downarrow$ ).

Infants in the delayed clamping group had higher birth weights, but, since birth weight was measured after the intervention, this was regarded as an outcome variable (see below).

\section{Primary outcome}

Four months post partum, at a mean (SD) age of 121 (5) days, 350 children $(92 \%)$ returned for assessment. There was no significant difference in haemoglobin concentration between the two groups (table $2 \Downarrow$ ). The study was powered to detect a $29 \%$ difference in ferritin concentrations, and the geometric mean serum ferritin concentration was $45 \%$ (95\% confidence interval $23 \%$ to $71 \%$ ) higher in the delayed cord clamping group (117 $\mu \mathrm{g} / \mathrm{L}$ with delayed clamping $v 81 \mu \mathrm{g} / \mathrm{L}$ with early clamping, $\mathrm{P}<0.001$ ). All other indicators of iron status (transferrin saturation, soluble transferrin receptors, reticulocyte haemoglobin, mean cell volume, and mean cell haemoglobin concentration) differed significantly between the groups (table $2 \Downarrow$ ). Iron deficiency was significantly more prevalent in the early clamping group, but the prevalence of anaemia did not differ between the groups (table $3 \Downarrow$ ). To prevent one case of iron deficiency, with or without anaemia, the number needed to treat was 20 (95\% confidence interval 17 to 67$)$.

\section{Secondary outcomes}

Neonatal blood samples were obtained at a median age of 2.4 days (range 1.9-4.9) from 357 (94\%) newborns. At this time, fewer infants in the delayed cord clamping group were anaemic than in the early cord clamping group $(2(1.2 \%) v 10(6.3 \%)$, $\mathrm{P}=0.02$, relative risk reduction 0.80 (95\% confidence interval
0.22 to 0.95 ), number needed to treat 20 (15 to 111$)$ ). No infant in either group was polycythaemic.

As for treatment with phototherapy, there was no significant difference between groups. Three infants were subjected to phototherapy, one in the delayed cord clamping group and two in the early clamping group (table $4 \Downarrow$ ).

There were no differences in the prevalence of neonatal respiratory symptoms (respiratory rate $>60$ breaths/minute, nostril flaring, grunting, or retractions between or under the ribs) between the delayed clamping and the early clamping groups, neither at 1 hour $(17(9.3 \%) v 12(6.6 \%), \mathrm{P}=0.4$, relative risk reduction $-0.39(-1.79$ to 0.31$))$, nor at 6 hours $(6(3.8 \%)$ $v 8(5.3 \%), \mathrm{P}=0.6$, relative risk reduction 0.28 ( -0.95 to 0.73$)$ ).

\section{Ancillary analyses}

Iron stores at 4 months of age were further assessed by calculating $\log$ TfR/Fer-ratio and total body iron, and these measures showed significant differences between the groups (table $2 \Downarrow$ ).

The measured amount of blood retained in the placenta was $37 \%$ (24\% to $48 \%$ ) lower in the delayed cord clamping group (geometric mean volume $25 \mathrm{~mL} v 39 \mathrm{~mL}, \mathrm{P}<0.001$ ). There were no group differences in cord blood iron status (not shown), but cord blood haemoglobin and packed cell volume were significantly lower in the delayed clamping group (table $1 \Downarrow$ ).

There was no difference between the delayed and early cord clamping groups in the proportion of infants who had started breast feeding at 1 hour $(135(74 \%) v 130(73 \%), \mathrm{P}=0.90$, relative risk reduction -0.01 ( -0.14 to 0.11$)$ ) or at 6 hours $(131$ $(82 \%) v 131(85 \%), \mathrm{P}=0.54$, relative risk reduction $0.03(-0.07$ to 0.12$)$ ). In the delayed clamping group 14 newborns $(7 \%)$ were admitted to the neonatal unit, compared with six $(3 \%)$ in the early cord clamping group $(\mathrm{P}=0.11$, relative risk reduction $-1.2(-4.7$ to 0.1$)$ ). The indications for admission in the delayed clamping group were transient tachypnoea $(n=2)$, suspected meconium aspiration $(n=2)$, pneumonia $(n=2)$, hypoglycaemia $(n=2)$, feeding difficulties $(n=2)$, need for phototherapy $(n=1)$, seizures $(n=1)$, cleft palate $(n=1)$, and mild asphyxia $(n=1)$. In the early clamping group reasons for admission were transient tachypnoea $(n=2)$, suspected meconium aspiration $(n=1)$, pneumonia $(\mathrm{n}=1)$, hypoglycaemia $(\mathrm{n}=1)$, and need for phototherapy $(\mathrm{n}=1)$.

At a median age of 2.4 days, mean haemoglobin levels and packed cell volume were significantly higher in the delayed cord clamping group, but there were no significant differences in iron status between the two groups (table $2 \Downarrow$ ). Bilirubin concentrations were similar in the two groups, and no differences were seen in the proportion of infants with hyperbilirubinaemia (>257 $\mu \mathrm{mol} / \mathrm{L})$ (table $4 \Downarrow$ ).

At 4 months of age, infants in the delayed and early cord clamping groups had similar weights (mean 6808 (SD 872) g $v 6864$ (843) g, $\mathrm{P}=0.5$, mean difference -56 ( -234 to 122$)$ ), and length $(64(2) \mathrm{cm} v 64(2) \mathrm{cm}, \mathrm{P}=0.4$, mean difference -0.2 $(-0.6$ to 0.3$))$. In the delayed cord clamping group, 97 (56\%) infants were exclusively breast fed compared with $89(51 \%)$ in the early clamping group $(\mathrm{P}=0.45$, relative risk reduction -0.09 $(-0.34$ to 0.11$))$. The proportion of infants exclusively or partially breast fed was $138(79 \%)$ in the delayed clamping group and $151(87 \%)$ in the early clamping group $(\mathrm{P}=0.09$, relative risk reduction 0.09 ( -0.01 to 0.17$)$ ). There was no significant difference regarding the proportion of iron deficiency: seven (4\%) exclusively breastfed infants had iron deficiency compared with four (3\%) among those receiving any 
amount of formula or solid food $(\mathrm{P}=0.6$, relative risk reduction $-0.5(-5.2$ to 0.6$))$.

\section{Discussion}

In term infants born after normal pregnancies, delaying clamping of the umbilical cord had significant effects on iron status at 4 months with higher serum ferritin concentration, less iron deficiency, and similar effects on all measured indicators of iron status except haemoglobin and packed cell volume. During the early neonatal period, we observed less anaemia in the delayed cord clamping group. There were no significant differences between groups with regard to neonatal respiratory symptoms or need for phototherapy.

\section{Strengths and limitations of the study}

This is one of the largest randomised controlled studies comparing delayed and early cord clamping in full term infants, and the first to assess effects on iron status beyond the neonatal period in a high income country. ${ }^{27}$ Iron is stored mainly in bone marrow and liver, and measurements using blood or serum are only indirect estimates. Consequently, such measurements have various limitations, including sensitivity to inflammation (ferritin, transferrin saturation), poor sensitivity for mild iron deficiency (haemoglobin, mean cell volume, mean cell haemoglobin concentration), or lack of reliable reference intervals (transferrin receptors and reticulocyte haemoglobin). ${ }^{40}$ By including a range of iron status indicators in addition to ferritin (all showing highly significant differences in iron status at 4 months of age in relation to time of umbilical cord clamping), our study offers strong evidence regarding iron status.

The study was not primarily designed or powered for assessing possible adverse effects of delayed cord clamping or other secondary outcomes, but our results are consistent with findings in other published studies.

One limitation in our study is that it was not possible to measure the amount of blood actually transfused from the placenta into the newborn child. There are, however, several indications that an increased placental transfusion occurred in the group subjected to delayed cord clamping, since infants in this group had $96 \mathrm{~g}$ higher birth weight, less blood retained in the placenta, and higher haemoglobin levels and packed cell volume at 2 days of age.

The level at which the baby is held before clamping also affects the speed and amount of placental transfusion. ${ }^{41}{ }^{42}$ To facilitate the placental transfusion, midwives were instructed to hold the infant at $20 \mathrm{~cm}$ below the vulva, which is slightly lower than in other studies that have used the level of the uterus ${ }^{20}$ or $10 \mathrm{~cm}$ below the vaginal introitus. ${ }^{17}{ }^{18}{ }^{21} \mathrm{We}$ did not measure the exact level each infant was held at. The recommended level was regarded as practical since it corresponded to the position of the lower part of the delivery bed. Neither did we assess exactly how long the babies were held in this position, since it would have been difficult to measure this and still mimic clinical practice.

Another limitation is that our study included only full term, low risk deliveries by healthy mothers from a well nourished population. The findings may not be generalisable to term infants with various perinatal risk factors such as maternal diabetes or intrauterine growth restriction.

Infant diet will also affect iron stores during infancy, ${ }^{43}$ and prolonged exclusive breast feeding may increase the risk of iron deficiency. ${ }^{44}$ However, we did not find higher prevalence of iron deficiency among the exclusively breastfed infants at 4 months old. Even though infant diet certainly is important for prevention of iron deficiency; from a public health perspective it is probably much easier to improve umbilical cord clamping policies than to improve dietary intakes in a whole population.

\section{Comparison with other studies}

Our observed effect of delayed cord clamping on ferritin levels at 4 months (a $45 \%$ increase) was similar to that found at 6 months in a Mexican trial, ${ }^{20}$ and, in accord with that trial, we observed no persisting effect on haemoglobin levels. Two meta-analyses, mainly based on trials in low and medium income settings, have shown that delayed cord clamping improves serum ferritin concentration at 3-6 months of age without affecting haemoglobin. ${ }^{16} 22$

It has been postulated that delayed cord clamping may increase the risk of neonatal polycythaemia and respiratory symptoms, but we did not find any group differences in these outcomes, which is also consistent with the Cochrane meta-analysis. ${ }^{16}$ Similar to results from two previous studies, ${ }^{45}{ }^{46}$ we found a higher risk of neonatal anaemia in the early cord clamping group, but no infant required treatment.

Fourteen infants in the delayed cord clamping group were admitted to the neonatal unit, compared with six in the early cord clamping group (non-significant difference), but only five of the admissions in the delayed clamping group and four of those in the early clamping group could reasonably be attributed to the intervention (transient tachypnoea, hypoglycaemia, and need for phototherapy). There have been inconsistent results on the possible association between delayed cord clamping and neonatal jaundice, and the Cochrane review that reported a significant increase in infants needing phototherapy for jaundice relied heavily on unpublished data. ${ }^{16}$ In our study there were no group differences in bilirubin concentrations or need for phototherapy even though we observed a relatively large difference in haemoglobin concentration at 2 days of age. Our results therefore strongly suggest that delayed cord clamping is not associated with any increase in the need of phototherapy in term infants, in agreement with the recent meta-analysis in $J A M A .^{22}$

We observed an unexpected difference in cord blood haemoglobin concentration; the delayed cord clamping group had $4.8 \mathrm{~g} / \mathrm{L}$ lower cord haemoglobin concentration than the early cord clamping group. A similar result was reported in the Cochrane report, with a mean difference in haemoglobin concentration of $4.2 \mathrm{~g} / \mathrm{L},{ }^{16}$ although this result was not discussed in the Cochrane report or in the original studies reporting this outcome. From the current data, we cannot explain the difference in cord haemoglobin. We speculate that the lower umbilical cord haemoglobin level and packed cell volume in the delayed cord clamping group could be due to changes in blood rheology or transendothelial plasma leakage in the umbilical cord after cord clamping, and that the difference does not reflect a true difference in haemoglobin level between the two groups before cord clamping.

\section{Interpretation of results}

We found significant differences between the intervention groups at 4 months of age in all measures of iron status except haemoglobin and packed cell volume, all pointing to an inferior iron status in the early cord clamping group. Lower ferritin concentrations, a higher log ratio of soluble transferrin receptor to ferritin, and lower total body iron index suggest depleted iron stores; lower transferrin saturation (calculated from serum iron and transferrin) and higher transferrin receptor levels suggest 
tissue iron deficiency; and lower mean cell volume, mean cell haemoglobin concentration, and reticulocyte haemoglobin suggest iron deficient erythropoiesis.

In the absence of anaemia, which is the marker of severe iron deficiency, our findings of abnormalities in several of these indicators (as used in our definition of iron deficiency) implies the presence of a moderate rather than a mild iron deficiency. The prevalence of iron deficiency was significantly higher in the early cord clamping group than in the delayed clamping group $(6 \% v 1 \%)$, which might have an impact on future neurodevelopment. ${ }^{50-12}$ The relation between non-anaemic iron deficiency and neurodevelopment is supported by a recent meta-analysis, which shows significant improvement of psychomotor development in non-anaemic infants given iron supplements. ${ }^{13}$

The lack of a persisting effect from delayed cord clamping on haemoglobin at 4 months of age can be explained by the physiological and gradual transfer of iron from erythrocytes to iron stores (measured by ferritin) as the haemoglobin concentration decreases and approaches its individual, genetically and environmentally determined "set point" some time after 2 months of age. This is supported by results from studies in Guatemala, India, and Mexico, which show effects of delayed cord clamping on haemoglobin at 2 months of age $\mathrm{e}^{19}$ and an effect on ferritin (but not haemoglobin) at 3-6 months. ${ }^{18} 20$ Only two infants fulfilled the criteria for iron deficiency anaemia at 4 months; both infants belonged to the early cord clamping group. This low prevalence was expected, since iron deficiency anaemia usually does not develop until after 4-6 months of age in term, normal birthweight infants, even in low or middle income countries with a high general prevalence of anaemia. ${ }^{37}$

\section{Conclusions and policy implications}

We conclude that delayed cord clamping, in this randomised controlled trial, resulted in improved ferritin levels and reduced the prevalence of iron deficiency at 4 months of age. Delayed clamping also reduced the prevalence of neonatal anaemia at 2 days of age without increasing the rate of respiratory symptoms or need for phototherapy in this sample of 382 full term infants born in a high income country. Two meta-analyses of clamping studies performed in low or middle income countries with a high general prevalence of anaemia found similar effects on ferritin as we did and concluded that this effect is clinically relevant and should lead to a change in practice. ${ }^{1622}$ Iron deficiency even without anaemia has been associated with impaired development among infants. Our results suggest that delayed cord clamping also benefits infant health in regions with a relatively low prevalence of iron deficiency and should be considered as standard care for full term deliveries after uncomplicated pregnancies. Further studies are needed to explore long term health effects of delayed and early cord clamping.

We thank Josefin Roswall and research nurses Eivor Kjellberg and Monika Nygren at the Department of Paediatrics, the staff at the Department of Obstetrics and Gynaecology, and all mothers and infants who participated in the study. We thank Associate Professor Amir Baigi and Professor Ulf Strömberg for valuable statistical advice.

Contributors: OA helped design the study; was responsible for staff training, study management, and data collection; and took part in data analysis and manuscript writing. LH-W helped design the study; advised on staff training, study management, and data collection; and took part in data analysis and manuscript writing. DA helped design the study; advised on staff training, study management, and data collection and analysis; and took part in manuscript writing. MD helped design the study; advised on staff training, study management, and data collection; and took part in data analysis and manuscript writing. $\mathrm{OA}$ and MD are guarantors for the study.

Funding: This study was supported by grants from the Regional Scientific Council of Halland; the HASNA Foundation, Halmstad; HRH Crown Princess Lovisa's Foundation for Child Care, Stockholm; and the Framework of Positive Scientific Culture, Hospital of Halland, Halmstad. The funders were not involved in the study design, data analysis, or manuscript preparation.

Competing interests: All authors have completed the ICMJE uniform disclosure form at www.icmje.org/coi_disclosure.pdf (available on request from the corresponding author) and declare: no support from any organisation for the submitted work; no financial relationships with any organisations that might have an interest in the submitted work in the previous three years; no other relationships or activities that could appear to have influenced the submitted work.

Ethical approval: The study was approved by the regional research ethics committee at Lund University (41/2008). Written informed consent was obtained by a midwife before the intervention.

Data sharing: No additional data available.

1 Van Rheenen PF, Brabin BJ. A practical approach to timing cord clamping in resource poor settings. BMJ 2006:333:954-8.

2 Bramhagen AC, Axelsson I. Iron status of children in southern Sweden: effects of cow's milk and follow-on formula. Acta Paediatr 1999;88:1333-7.

3 Thane CW, Walmsley CM, Bates CJ, Prentice A, Cole TJ. Risk factors for poor iron status in British toddlers: further analysis of data from the National Diet and Nutrition Survey of children aged 1.5-4.5 years. Public Health Nutr 2000:3:433-40.

4 Persson LA, Lundstrom M, Lonnerdal B, Hernell O. Are weaning foods causing impaired iron and zinc status in 1-year-old Swedish infants? A cohort study. Acta Paediatr 1998;87:618-22.

5 Beard J. Recent evidence from human and animal studies regarding iron status and infant development. J Nutr 2007:137:524-30S.

6 Carlson ES, Tkac I, Magid R, O'Connor MB, Andrews NC, Schallert T, et al. Iron is essential for neuron development and memory function in mouse hippocampus. $J$ Nutr 2009;139:672-9.

7 Lozoff B, Brittenham GM, Wolf AW, McClish DK, Kuhnert PM, Jimenez E, et al. Iron deficiency anemia and iron therapy effects on infant developmental test performance. Pediatrics 1987;79:981-95.

8 McCann JC, Ames BN. An overview of evidence for a causal relation between iron deficiency during development and deficits in cognitive or behavioral function. Am J Clin Nutr 2007;85:931-45.

9 Gunnarsson BS, Thorsdottir I, Palsson G, Gretarsson SJ. Iron status at 1 and 6 years versus developmental scores at 6 years in a well-nourished affluent population. Acta Paediatr 2007:96:391-5.

10 Thomas DG, Grant SL, Aubuchon-Endsley NL. The role of iron in neurocognitive development. Dev Neuropsychol 2009;34:196-222.

11 Grantham-McGregor S, Ani C. A review of studies on the effect of iron deficiency on cognitive development in children. J Nutr 2001;131:649-68S.

12 Lozoff B, Beard J, Connor J, Barbara F, Georgieff M, Schallert T. Long-lasting neural and behavioral effects of iron deficiency in infancy. Nutr Rev 2006;64:S34-43.

13 Szajewska H, Ruszczynski M, Chmielewska A. Effects of iron supplementation in nonanemic pregnant women, infants, and young children on the mental performance and psychomotor development of children: a systematic review of randomized controlled trials. Am J Clin Nutr 2010;91:1684-90.

14 Sachdev H, Gera T, Nestel P. Effect of iron supplementation on mental and motor development in children: systematic review of randomised controlled trials. Public Health Nutr 2005;8:117-32.

15 Yao AC, Moinian M, Lind J. Distribution of blood between infant and placenta after birth Lancet 1969;2:871-3.

16 McDonald SJ, Middleton P. Effect of timing of umbilical cord clamping of term infants on maternal and neonatal outcomes. Cochrane Database Syst Rev 2008;2:CD004074.

17 Geethanath RM, Ramij S, Thirupuram S, Rao YN. Effect of timing of cord clamping on the iron status of infants at 3 months. Indian Pediatr 1997;34:103-6.

18 Gupta R, Ramji S. Effect of delayed cord clamping on iron stores in infants born to anemic mothers: a randomized controlled trial. Indian Pediatr 2002;39:130-5.

19 Grajeda R, Perez-Escamilla R, Dewey KG. Delayed clamping of the umbilical cord improves hematologic status of Guatemalan infants at 2 mo of age. Am J Clin Nutr 1997;65:425-31.

20 Chaparro CM, Neufeld LM, Tena Alavez G, Eguia-Liz Cedillo R, Dewey KG. Effect of timing of umbilical cord clamping on iron status in Mexican infants: a randomised controlled trial. Lancet 2006;367:1997-2004.

21 Van Rheenen P, de Moor L, Eschbach S, de Grooth H, Brabin B. Delayed cord clamping and haemoglobin levels in infancy: a randomised controlled trial in term babies. Trop Med Int Health 2007;12:603-16.

22 Hutton EK, Hassan ES. Late vs early clamping of the umbilical cord in full-term neonates: systematic review and meta-analysis of controlled trials. JAMA 2007;297:1241-52.

23 Male C, Persson LA, Freeman V, Guerra A, van't Hof MA, Haschke F. Prevalence of iron deficiency in 12-mo-old infants from 11 European areas and influence of dietary factors on iron status (Euro-Growth study). Acta Paediatr 2001;90:492-8.

24 Looker AC, Dallman PR, Carroll MD, Gunter EW, Johnson CL. Prevalence of iron deficiency in the United States. JAMA 1997;277:973-6. 


\section{What is already known on this subject}

Delaying umbilical cord clamping for two to three minutes results in a substantial transfusion of blood from the placenta into the newborn child

This transfusion improves iron status in infants within the first months of life in countries with a high prevalence of iron deficiency anaemia, but has been suggested to increase the risk of neonatal jaundice and neonatal cardiopulmonary problems

Iron deficiency even without anaemia has been associated with impaired development among infants

\section{What this study adds}

Delayed cord clamping improved iron status and decreased the risk for iron deficiency at 4 months of age among infants born at term in a country with a low prevalence of iron deficiency anaemia

Delayed clamping was not associated with neonatal jaundice or other adverse effects

25 Yao AC, Lind J, Vuorenkoski V. Expiratory grunting in the late clamped normal neonate. Pediatrics 1971:48:865-70.

26 Saigal S, Usher RH. Symptomatic neonatal plethora. Biol Neonate 1977;32:62-72.

27 Van Rheenen P, Brabin BJ. Late umbilical cord-clamping as an intervention for reducing iron deficiency anaemia in term infants in developing and industrialised countries: a systematic review. Ann Trop Paediatr 2004:24:3-16.

28 Winter C, Macfarlane A, Deneux-Tharaux C, Zhang WH, Alexander S, Brocklehurst P, et al. Variations in policies for management of the third stage of labour and the immediate management of postpartum haemorrhage in Europe. BJOG 2007;114:845-54.

29 Dallman PR. Red blood cell values at various ages. In: Rudolph A, ed. Pediatrics . 16th ed. Appleton-Centrury-Crofts, 1977:1111.

30 Pappas A, Delaney-Black V. Differential diagnosis and management of polycythemia. Pediatr Clin North Am 2004:51:1063-86.

31 Domellöf M, Dewey KG, Lönnerdal B, Cohen RJ, Hernell O. The diagnostic criteria for iron deficiency in infants should be re-evaluated. J Nutr 2002;132:3680-6.

32 Saarinen UM, Siimes MA. Developmental changes in serum iron, total iron-binding capacity, and transferrin saturation in infancy. J Pediatr 1977:91:875-7.

33 Pfeiffer CM, Cook JD, Mei Z, Cogswell ME, Looker AC, Lacher DA. Evaluation of an automated soluble transferrin receptor (sTfR) assay on the Roche Hitachi analyzer and its comparison to two ELISA assays. Clin Chim Acta 2007;382:112-6.

34 Malope BI, MacPhail AP, Alberts M, Hiss DC. The ratio of serum transferrin receptor and serum ferritin in the diagnosis of iron status. Br J Haematol 2001;115:84-9.

35 Cook JD, Flowers $\mathrm{CH}$, Skikne BS. The quantitative assessment of body iron. Blood 2003;101:3359-63.

36 Mei Z, Cogswell ME, Parvanta I, Lynch S, Beard JL, Stoltzfus RJ, et al. Hemoglobin and ferritin are currently the most efficient indicators of population response to iron interventions: an analysis of nine randomized controlled trials. J Nutr 2005;135:1974-80.

37 Domellof M, Cohen RJ, Dewey KG, Hernell O, Rivera LL, Lonnerdal B. Iron supplementation of breast-fed Honduran and Swedish infants from 4 to 9 months of age. J Pediatr 2001;138:679-87.
38 Hodges $\mathrm{JL} \mathrm{Jr}$, Lehmann EL. Estimates of location based on rank tests. Ann Math Stat 1963;34:598-611.

39 Pezzullo JC. JavaStat: 2-way contingency table analysis. http://statpages.org/ctab2×2 html.

40 Domellof M. Iron requirements, absorption and metabolism in infancy and childhood. Curr Opin Clin Nutr Metab Care 2007:10:329-35.

41 Yao AC, Lind J. Effect of gravity on placental transfusion. Lancet 1969;2:505-8.

42 Nelle M, Zilow EP, Kraus M, Bastert G, Linderkamp O. The effect of Leboyer delivery on blood viscosity and other hemorheologic parameters in term neonates. Am J Obstet Gynecol 1993;169:189-93.

43 Chantry CJ, Howard CR, Auinger P. Full breastfeeding duration and risk for iron deficiency in US infants. Breastfeed Med 2007;2:63-73.

44 Fewtrell M, Wilson DC, Booth I, Lucas A. Six months of exclusive breast feeding: how good is the evidence? BMJ 2011;342:c5955.

45 Ceriani Cernadas JM, Carroli G, Pellegrini L, Otano L, Ferreira M, Ricci C, et al. The effect of timing of cord clamping on neonatal venous hematocrit values and clinical outcome at term: a randomized, controlled trial. Pediatrics 2006;117:e779-86.

46 Emhamed MO, van Rheenen P, Brabin BJ. The early effects of delayed cord clamping in term infants born to Libyan mothers. Trop Doct 2004;34:218-22.

Accepted: 29 September 2011

\section{Cite this as: BMJ 2011;343:d7157}

This is an open-access article distributed under the terms of the Creative Commons Attribution Non-commercial License, which permits use, distribution, and reproduction in any medium, provided the original work is properly cited, the use is non commercial and is otherwise in compliance with the license. See: http://creativecommons.org/licenses/bync/2.0/ and http://creativecommons.org/licenses/by-nc/2.0/legalcode. 


\section{Tables}

Table 1| Baseline characteristics of mother-infant dyads who participated in randomised trial of early umbilical cord clamping ( $\leq 10 \mathbf{s}$ after delivery) versus delayed clamping ( $\geq 180 \mathrm{~s}$ ). Values are means (SD) unless stated otherwise

Cord clamping

Early $(n=189)$ Delayed $(n=193) \quad P$ value of difference

Maternal characteristics

\begin{tabular}{lccc}
\hline Age (years) & $31.6(4.2)$ & $30.9(4.7)$ & $\mathrm{NS}$ \\
\hline Parity (including study child) & $1.76(0.85)$ & $1.74(0.73)$ & $\mathrm{NS}$ \\
\hline Weight at first antenatal visit $(\mathrm{kg})$ & $66.6(12.1)$ & $67.4(12.0)$ & $\mathrm{NS}$ \\
\hline Body mass index & $23.8(4.0)$ & $24.2(3.7)$ & $\mathrm{NS}$ \\
\hline Haemoglobin at first antenatal visit (g/L) & $128(9)$ & $128(11)$ & $\mathrm{NS}$ \\
\hline No (\%) with Rh negative blood group & $27(14)$ & $40(21)$ & $\mathrm{NS}$ \\
\hline No (\%) of vaginal deliveries: & & $174(90)$ & $\mathrm{NS}$ \\
\hline Non-instrumental & $176(93)$ & $16(8)$ & $\mathrm{NS}$ \\
\hline Vacuum extraction & $11(6)$ & $1(0.5)$ & $\mathrm{NS}$ \\
\hline Forceps & $1(0.5)$ & $2(1)$ & $\mathrm{NS}$ \\
\hline No (\%) of caesarean sections & & $40.0(1.1)$ & $\mathrm{NS}$ \\
\hline Infant characteristics & $40.1(1.1)$ & $86(45)$ & $\mathrm{NS}$ \\
\hline Gestational age (weeks) & $93(49)$ & $188(97)$ & $\mathrm{NS}$ \\
\hline No (\%) of males & $181(96)$ & $3629(460)$ & $0.05^{\star}$ \\
\hline No (\%) with Apgar score 7-10 at 1 minute & $3533(486)$ & $50.9(1.9)$ & $\mathrm{NS}$ \\
\hline Birth weight (g) & $50.8(1.9)$ & $34.9(1.4)$ & $\mathrm{NS}$ \\
\hline Birth length (cm) & $34.7(1.4)$ & $159(18)$ & $0.01 \dagger$ \\
\hline Head circumference (cm) & $0.49(0.04)$ & & \\
\hline Umbilical cord haemoglobin (g/L) & & & \\
\hline Umbilical cord packed cell volume & $163)$ & & \\
\hline
\end{tabular}

NS=Not significant $(P>0.05)$.

*Mean difference $96 \mathrm{~g}(95 \% \mathrm{Cl} 0.3$ to 191$)$.

†Mean difference $-4.7 \mathrm{~g} / \mathrm{L}(95 \% \mathrm{Cl}-8.4$ to -1.1$)$.

$\ddagger$ Mean difference -0.013 (95\% $\mathrm{Cl}-0.024$ to -0.003 ). 
Table 2| Measures of complete blood count and iron status at 2 days and 4 months of age in infants who were randomised to early umbilical cord clamping ( $\leq 10 \mathrm{~s}$ after delivery) or delayed clamping ( $\geq 180 \mathrm{~s}$ ). Values are means (SD) unless stated otherwise

\begin{tabular}{|c|c|c|c|c|c|c|}
\hline & \multicolumn{3}{|c|}{2 days } & \multicolumn{3}{|c|}{4 months } \\
\hline & \multicolumn{2}{|c|}{ Cord clamping } & \multirow{2}{*}{$\begin{array}{c}\text { Difference }(95 \% \mathrm{Cl}), \mathrm{P} \\
\text { value }\end{array}$} & \multicolumn{2}{|c|}{ Cord clamping } & \multirow{2}{*}{$\begin{array}{c}\text { Difference }(95 \% \mathrm{Cl}), \mathrm{P} \\
\text { value }\end{array}$} \\
\hline & Early & Delayed & & Early & Delayed & \\
\hline Blood count & $(n=160)$ & $(n=162)$ & & $(n=175)$ & $(n=168)$ & \\
\hline Haemoglobin $(g / L)$ & $175(19)$ & $189(17)$ & $\begin{array}{c}13.5 \text { (9.6 to } 17.5), \\
<0.001\end{array}$ & $113(7)$ & $113(8)$ & 0.0 (-1.6 to 1.6$), 0.98$ \\
\hline Packed cell volume & $50(5)$ & $53(5)$ & 3.5 (2.4 to 4.6$),<0.001$ & $33(2)$ & $33(2)$ & -0.2 ( -0.7 to 0.2$), 0.28$ \\
\hline Mean cell volume (fL) & $98.3(3.8)$ & $98.4(3.7)$ & 0.1 (-0.7 to 0.9$), 0.82$ & $78.0(3.1)$ & $79.0(3.2)$ & 1.0 (0.3 to 1.7$), 0.004$ \\
\hline $\begin{array}{l}\text { Mean cell haemoglobin } \\
\text { concentration }(\mathrm{g} / \mathrm{L})\end{array}$ & $354(7)$ & $356(8)$ & 2.2 (0.6 to 3.9 ), 0.008 & $344(0.8)$ & $346(0.8)$ & 2.6 (0.9 to 4.3 ), 0.002 \\
\hline $\begin{array}{l}\text { Reticulocyte } \\
\text { haemoglobin (pg/L) }\end{array}$ & $32.5(2.4)$ & $32.7(2.6)$ & 0.2 (-0.4 to 0.7$), 0.54$ & $28.9(2.1)$ & $29.6(1.9)$ & 0.6 (0.2 to 1.0$), 0.005$ \\
\hline $\begin{array}{l}\text { Reticulocyte count } \\
\left(\times 10^{9} / \mathrm{L}\right)\end{array}$ & $171(47)$ & $168(44)$ & -3 (-13 to 7$), 0.54$ & $37(11)$ & $40(11)$ & 2.5 (0.1 to 4.8 ), 0.04 \\
\hline \multicolumn{7}{|l|}{ Iron status* } \\
\hline Iron $(\mu \mathrm{mol} / \mathrm{L})$ & $9.9(2.9)$ & $9.9(2.7)$ & $-0.1(-0.7$ to 0.6$), 0.88$ & $9.3(2.9)$ & $10.2(3.0)$ & 0.9 (0.2 to 1.5$), 0.007$ \\
\hline Transferrin $(\mathrm{g} / \mathrm{L})$ & $1.76(0.26)$ & $1.76(0.22)$ & $0.0(-0.05$ to 0.05$), 0.99$ & $2.41(0.34)$ & $2.28(0.31)$ & $\begin{array}{c}-0.12(-0.19 \text { to }-0.06) \\
<0.001\end{array}$ \\
\hline $\begin{array}{l}\text { Transferrin receptors } \\
\text { (mg/L) }\end{array}$ & $5.35(1.60)$ & $5.44(1.64)$ & $\begin{array}{c}0.09(-0.26 \text { to } 0.45), \\
0.61\end{array}$ & $3.97(0.80)$ & $3.73(0.69)$ & $\begin{array}{c}-0.24(-0.40 \text { to }-0.08) \\
0.003\end{array}$ \\
\hline $\begin{array}{l}\text { Transferrin saturation } \\
(\%)\end{array}$ & $23(7)$ & $23(7)$ & $0.4(-1.9$ to 1.2$), 0.65$ & $16(6)$ & $18(6)$ & 2.4 (1.2 to 3.7$),<0.001$ \\
\hline $\begin{array}{l}\text { Geometric mean (range) } \\
\text { ferritin }(\mu \mathrm{g} / \mathrm{L})\end{array}$ & $300(44-628)$ & $312(110-1029)$ & $4.0(-6.5$ to 15.1$) \dagger, 0.45$ & $81(6-760)$ & $117(20-880)$ & $45(23$ to 71$) \dagger,<0.001$ \\
\hline LogTfR/Fer & $1.41(0.27)$ & $1.40(0.25)$ & $\begin{array}{c}-0.01(-0.07 \text { to } 0.05) \\
0.74\end{array}$ & $1.85(0.43)$ & $1.66(0.33)$ & $\begin{array}{c}-0.19(-0.27 \text { to }-0.11) \\
<0.001\end{array}$ \\
\hline Total body iron (mg/kg) & $11.7(2.2)$ & $11.8(2.1)$ & 0.1 (-0.4 to 0.6$), 0.74$ & $8.1(3.5)$ & $9.6(2.7)$ & 1.6 (0.9 to 2.3$),<0.001$ \\
\hline
\end{tabular}

LogTfR/Fer=log ratio of transferrin receptor and ferritin.

*Numbers of successful analyses of iron status for early and delayed clamping groups were: at 2 days, iron and transferrin saturation ( $\mathrm{n}=137,146)$, transferrin $(n=155,158)$, transferrin receptors $(n=156,157)$, and ferritin, LogTfR/Fer, and total body iron $(n=152,156)$; at 4 months, iron, ferritin, LogTfR/Fer, total body iron, and transferrin receptors $(n=175,172)$, transferrin and transferrin saturation $(n=175,171)$

†Geometric mean ratio in percentage. 
Table 3| Proportion of infants randomised to early umbilical cord clamping ( $\leq 10 \mathrm{~s}$ after delivery) or delayed clamping ( $\geq 180 \mathrm{~s})$ who had iron status indicators outside reference limits at 4 months old. Values are numbers (percentages) unless stated otherwise

\begin{tabular}{|c|c|c|c|c|c|}
\hline & \multicolumn{2}{|c|}{ Cord clamping } & \multirow[b]{2}{*}{$P$ value } & \multirow{2}{*}{$\begin{array}{l}\text { Relative risk reduction }(95 \% \\
\mathrm{Cl})\end{array}$} & \multirow{2}{*}{$\begin{array}{l}\text { Number needed to treat } \\
\qquad(95 \% \mathrm{Cl})\end{array}$} \\
\hline & Early $(n=175)$ & Delayed $\left(n=172^{*}\right)$ & & & \\
\hline Ferritin $<20 \mu \mathrm{g} / \mathrm{L}$ & $13(7.4)$ & $0(0.0)$ & $<0.001$ & $1.0(0.71-1.00)$ & 14 (14 to 25$)$ \\
\hline Mean cell volume $<73 \mathrm{fL}$ & $9(5.1)$ & $4(2.4)$ & 0.26 & $0.54(-0.39$ to 0.85$)$ & NA \\
\hline Transferrin saturation $<10 \%$ & $24(13.7)$ & $10(5.8)$ & 0.02 & $0.57(0.15$ to 0.79$)$ & 13 (8 to 62$)$ \\
\hline Transferrin receptors $>7 \mathrm{mg} / \mathrm{L}$ & 0 & 0 & NA & NA & NA \\
\hline Iron deficiency $†$ & $10(5.7)$ & $1(0.6)$ & 0.01 & $0.90(0.38$ to 0.98$)$ & 20 (17 to 67$)$ \\
\hline Anaemia $(\mathrm{Hb}<105 \mathrm{~g} / \mathrm{L})$ & $21(1.2)$ & $21(1.25)$ & 1.0 & $-0.04(-0.83$ to 0.41$)$ & NA \\
\hline
\end{tabular}

$\mathrm{NA}=$ not applicable.

*Number of successful analyses were 168 for mean cell volume and anaemia, 171 for transferrin saturation, and 166 for iron deficiency.

†Defined as $\geq 2$ iron indicators (low ferritin, low mean cell volume, low transferrin saturation, high transferrin receptors) outside reference range. 
Table 4| Hyperbilirubinaemia and need for phototherapy at 2 days old among infants randomised to early umbilical cord clamping ( $\leq 10 \mathrm{~s}$ after delivery) or delayed clamping ( $\geq 180 \mathrm{~s}$ ). Values are numbers (percentages) unless stated otherwise

\begin{tabular}{|c|c|c|c|c|}
\hline & \multicolumn{2}{|c|}{ Cord clamping } & \multirow[b]{2}{*}{$P$ value } & \multirow[b]{2}{*}{ Relative risk reduction $(95 \% \mathrm{Cl})$} \\
\hline & Early $(n=189)$ & Delayed $(n=192)$ & & \\
\hline Mean (SD) bilirubin $(\mu \mathrm{mol} / \mathrm{L})^{*}$ & $144(62)$ & $145(67)$ & $0.96 \dagger$ & \\
\hline Bilirubin $>257 \mu \mathrm{mol} / \mathrm{L}^{*}$ & $7(5.4)$ & $4(2.9)$ & 0.37 & $0.46(-0.70$ to 0.83$)$ \\
\hline Treated with phototherapy & $2(1.1)$ & $1(0.5)$ & 0.62 & $0.52(-2.7$ to 0.94$)$ \\
\hline
\end{tabular}

${ }^{*}$ Numbers of successful analyses of bilirubin for early and delayed clamping groups were 129 and 136 . †Mean difference $0.4 \mu \mathrm{mol} / \mathrm{L}(95 \% \mathrm{Cl}-15.2$ to 16.1$)$. 


\section{Figure}

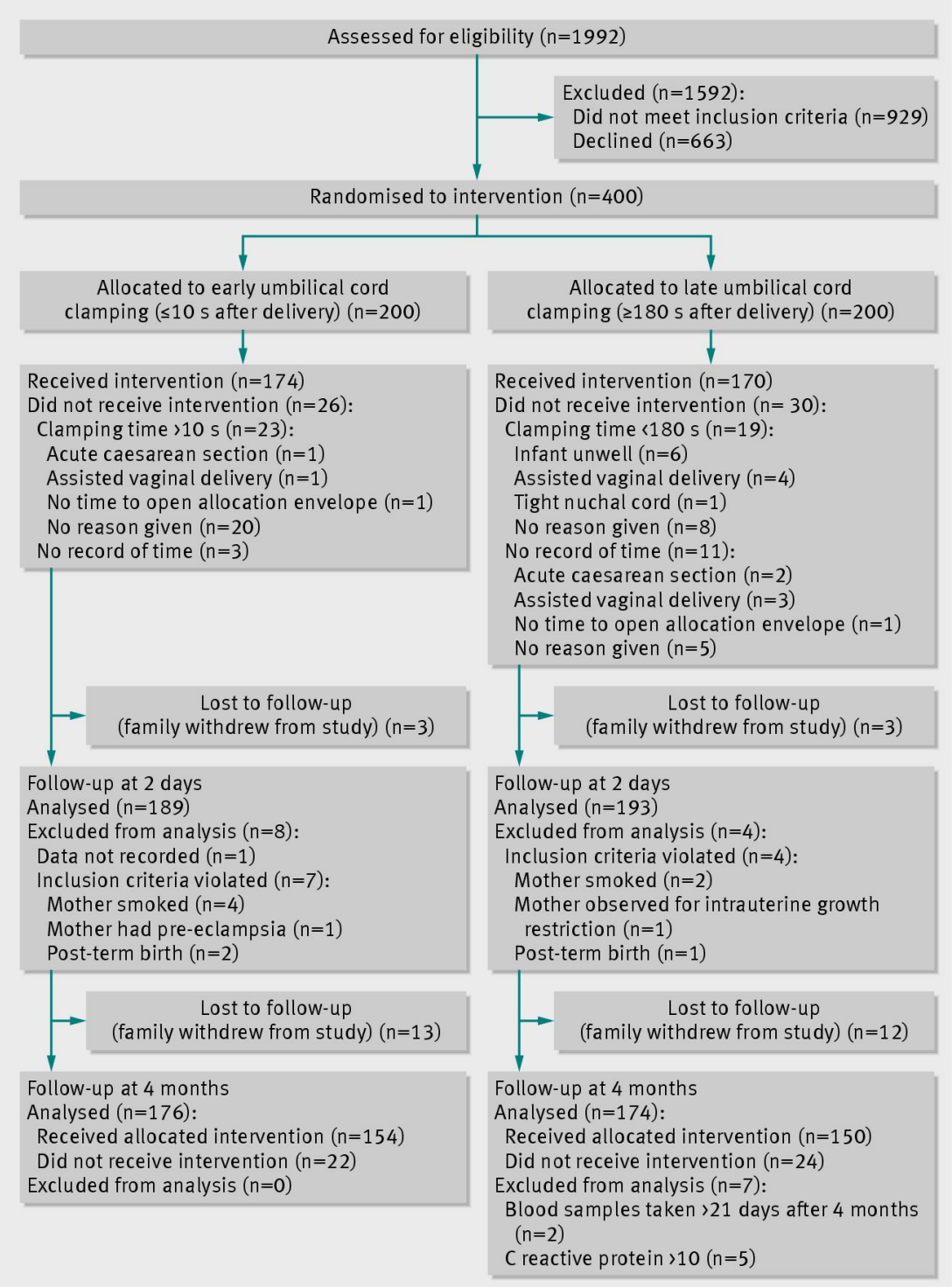

Participant flow through study 